Aluísio J. D. Barros 1 Evandro V. Gonçalves ${ }^{1}$ Cátia R. S. de Borba 1 Cláudia S. Lorenzatto 1 Débora B. Motta 1 Vera Regina L. da Silva 1 Viviane M. Schiroky 1

\section{Perfil das creches de uma cidade de porte médio do sul do Brasil: operação, cuidados, estrutura física e segurança}

\author{
Daycare centers in a medium-sized Brazilian \\ city: operations, child-care practices, \\ infrastructure, and safety
}

\footnotetext{
1 Departamento de Medicina Social, Universidade Federal de Pelotas. C. P. 464. Pel otas, RS 96001-970, Brasil. abarros@ufpel.tche.com.br
}

Abstract Ninety-two daycare centers (23 public, 10 charitable, and 59 private) were identified in the municipality of Pelotas, Rio Grande do Sul, Southern Brazil. These centers were studied in relation to their organization, services, child-care practices, and infrastructure. All public centers worked full-time, while most private centers operated in the afternoon and received a smaller proportion of children under the age of two. The child-to-attendant ratio was si milar in both types of centers, and the nurseries were the classes most frequently above the recommended maximum. Group and center si zes were larger in the public centers. Attendant school ing was higher in the private centers, but task specificity was lower. The infrastructure deficiencies most commonly observed in the public centers were lack of an internal recreational area and playground equipment. Private centers lacked adequate diapering facilities and exclusi ve toilets for the children. A small proportion of centers had staff trained to handle fire emergencies and administer first aid, revealing insufficient concern over safety issues.

Key words Child Day Care Centers; Child Care; Legislation; Children

Resumo Foram identificadas 92 creches (23 públicas, 10 filantrópicas e 59 privadas) no Municípi o de Pel otas, Rio Grande do Sul, das quais se estudaram aspectos da organização, práticas de cuidado e estrutura física. As creches públicas funcionavam em período integral, enquanto que as privadas funcionavam principal mente à tarde e recebiam um proporção menor de crianças até 2 anos. A relação criança por monitora foi semelhante para os dois tipo de creche, sendo que o berçário foi a classe em que esta relação estava acima do recomendado com maior freqüência. O número total de crianças nas classes e creches foi maior nas públicas. As monitoras das creches privadas tinham, em média, mais anos de escolaridade. Por outro lado, encontrou-se um grau mais al to de especialização de tarefas nas creches públicas. As deficiências mais comuns de infra-estrutura nas creches públicas foram a falta de recreio coberto e brinquedos no recrei o externo, enquanto que nas privadas foram a falta de fral dários e banhei ros exclusi vos para as crianças. Uma pequena proporção das creches contava com funci onários treinados para prestar primei ros socorros e combater incêndios, revelando baixa preocupação com segurança. Palavras-chave Creches; Cuidado da Criança; Crianças; Legislação 


\section{Introdução}

Em países desenvolvidos e em desenvolvimento, o uso de serviços de cuidado infantil está se tornando cada vez mais comum. Calcula-se que nos Estados Unidos cerca de $30 \%$ de todas as crianças pré-escolares freqüentem algum tipo de serviço de cuidado infantil fora de suas residências (Haskins \& Kotch, 1986; Osterholm et al., 1992; Holaday et al., 1995). No Brasil, sabe-se hoje que nas cidades médias e grandes 10 a $15 \%$ dos pré-escolares freqüentam creches gratuitas (Barros, 1996; Barros et al., 1998). Este número deve aumentar consideravelmente se contarmos também as crianças freqüentando creches particulares. Além disso, a demanda por estes serviços é grande e tende a aumentar com a participação crescente da mulher no mercado de trabalho.

Do ponto de vista da saúde coletiva, esta é uma área que requer atenção especial. Os trabalhos científicos existentes são praticamente unânimes em mostrar que as crianças que freqüentam creches adoecem mais freqüentemente que as crianças cuidadas exclusivamente em casa (Haskins \& Kotch, 1986; Barros, 1999). Em particular, crianças que freqüentam creches apresentam uma ocorrência de pneumonia 2 a 12 vezes maior que as crianças cuidadas em casa ( Victora et al., 1994; Fonseca et al., 1996; Marbury et al., 1997). Diarréia é outro problema que ocorre com freqüência 60 a $250 \%$ maior nas crianças em creches (Alexander et al., 1990; Hillis et al., 1992).

Desta forma, cabe aos profissionais engajados na área de saúde coletiva trabal har para que nossas crianças tenham acesso a creches de boa qualidade, não só do ponto de vista pedagógico, mas também em relação às práticas de cuidado, de forma a minimizar os riscos à saúde. Isto deve ser feito por meio de orientação, normatização e controle.

Nosso objetivo principal com este estudo foi traçar um perfil das creches públicas, filantrópicas e privadas de um município de médio porte no Brasil (Pelotas, RS). Pretendeu-se determinar o número de creches institucionais em funcionamento no município e o número de crianças atendidas, descrever as creches quanto a características operacionais, estrutura física, práticas de cuidado e aspectos de segurança, e contrapor as características encontradas à legislação e recomendações existentes.

\section{Metodologia}

A coleta de dados foi realizada no Município de Pelotas, RS, no período compreendido entre julho e setembro de 1997. As creches municipais foram identificadas por intermédio do Movimento Assistencial de Pelotas (M APEL) e as demais creches pela Assistência Social da Delegacia Regional de Saúde e pelo Departamento de Ação Sanitária da Secretaria Municipal de Saúde e Bem Estar. À listagem assim obtida foram acrescentadas creches encontradas no catálogo telefônico.

Foram identificadas 99 creches, sendo que em 7 delas não se realizou a entrevista: 5 por terem fechado, uma por trabalhar com crianças excepcionais e outra por atender somente crianças acima de 7 anos. Assim, foram estudadas 92 creches, 23 públicas, 10 filantrópicas e 59 privadas.

Uma carta com informações sobre os objetivos do estudo e o tipo de colaboração desejada foi enviada à direção das creches. As entrevistas, previamente agendadas por telefone, foram realizadas com a diretora, a administradora ou a proprietária, nesta ordem de preferência, nas próprias creches.

Foi utilizado um questionário padronizado, contendo questões fechadas, pré-codificadas e algumas questões abertas. Coletou-se informação sobre características operacionais, práticas de cuidado, estrutura física e segurança das creches. $\mathrm{O}$ questionário foi pré-testado e aplicado por uma nutricionista e estudantes de medicina, todos submetidos a treinamento prévio.

Os grupos de crianças foram classificados em níveis - berçário, maternal, jardim e pré de acordo com os critérios mais comuns adotados pelas próprias creches e documentos relevantes (Rodrigues, 1992; Governo do Estado do Rio Grande do Sul, 1990; Ministério da Saúde, 1989). O berçário ficou definido como o nível que recebe crianças de 0 a 23 meses (até 1 ano completo), o maternal, o nível de crianças de 24 a 47 meses ( 2 a 3 anos completos), o jardim, o nível de crianças de 48 a 71 meses ( 4 a 5 anos completos) e o pré, com crianças de 72 a 83 meses (6 anos completos).

Os regimes de funcionamento foram definidos como integral (pelo menos 8 horas diárias), parcial (pelo menos 4 horas diárias) e misto (integral e parcial). 
Resultados

Operação

Das 92 creches da área urbana do Município de Pelotas, 59 (64\%) eram privadas, 23 (25\%) públicas e 10 (11\%) filantrópicas. A análise foi realizada, em sua maior parte, separadamente para estes três grupos, devido às grandes diferenças encontradas.

Todas as creches públicas funcionavam em regime integral. Entre as filantrópicas, 7 (70\%) funcionavam em regime misto e 3 (30\%) em regime parcial. De forma inversa, 43 (73\%) creches privadas funcionavam em regime parcial e 16 (27\%) em regime misto. Apenas uma delas operava em regime integral.

No total, encontramos 4.403 crianças freqüentando creches, $13,7 \%$ das crianças de 0 a 6 anos da área urbana do município (IBGE, 1996). Destas, 1.650 (37\%) estavam em creches públicas, 751 (17\%) em creches filantrópicas e 2.002 (46\%) em creches privadas. Todas as crianças das creches públicas freqüentavam em período integral. Nas creches filantrópicas e privadas este percentual foi de $61 \%$ e $7 \%$, respectivamente. O período da tarde foi o que concentrou a maioria das crianças (89\%) das creches privadas.

O número médio de crianças por creche foi de 72, 75 e 59 para creches públicas, filantrópicas e privadas, respectivamente. A Figura 1 mostra a distribuição do número de crianças por creche, para cada tipo. Das creches públicas, $86 \%$ atendiam entre 50 e 99 crianças, sendo que a maior delas atendia 110 crianças. As creches privadas eram menores, com cerca de $50 \%$ delas recebendo até 24 crianças, a maior com 145 crianças. As creches filantrópicas apresentaram uma variabilidade bem maior: $70 \%$ delas recebiam de 25 a 99 crianças, e o número total de crianças variou de 19 a 205.

A distribuição do número de crianças por nível foi bastante diferente entre os três tipos de creche. As públicas tinham a distribuição mais uniforme, com $21 \%$ das crianças no berçário, 33\% no maternal, 27\% no jardim e 19\% no pré. As filantrópicas apresentaram maior concentração de crianças no maternal (42\%) e no jardim (34\%), recebendo uma proporção menor de crianças de berçário ( $17 \%$ ) e de pré (7\%). Esta concentração foi ainda mais evidente entre as creches privadas, com apenas $10 \%$ das crianças no berçário, e 4\% no pré. A maioria das crianças era do maternal (40\%) e do jardim (46\%).

Foram calculados o número total de crianças para cada grupo (também referido como tamanho do grupo) e o número de crianças por monitora (a funcionária responsável por cuidar das crianças). A Tabela 1 mostra a média de crianças por grupo e de crianças por monitora para cada nível e tipo de creche.

O tamanho médio dos grupos das creches filantrópicas foi semelhante ao das creches públicas para o berçário e o maternal e um pouco

Figura 1

Distribuição do número total de crianças por creche, para creches públicas, filantrópicas e privadas de Pelotas, Rio Grande do Sul.

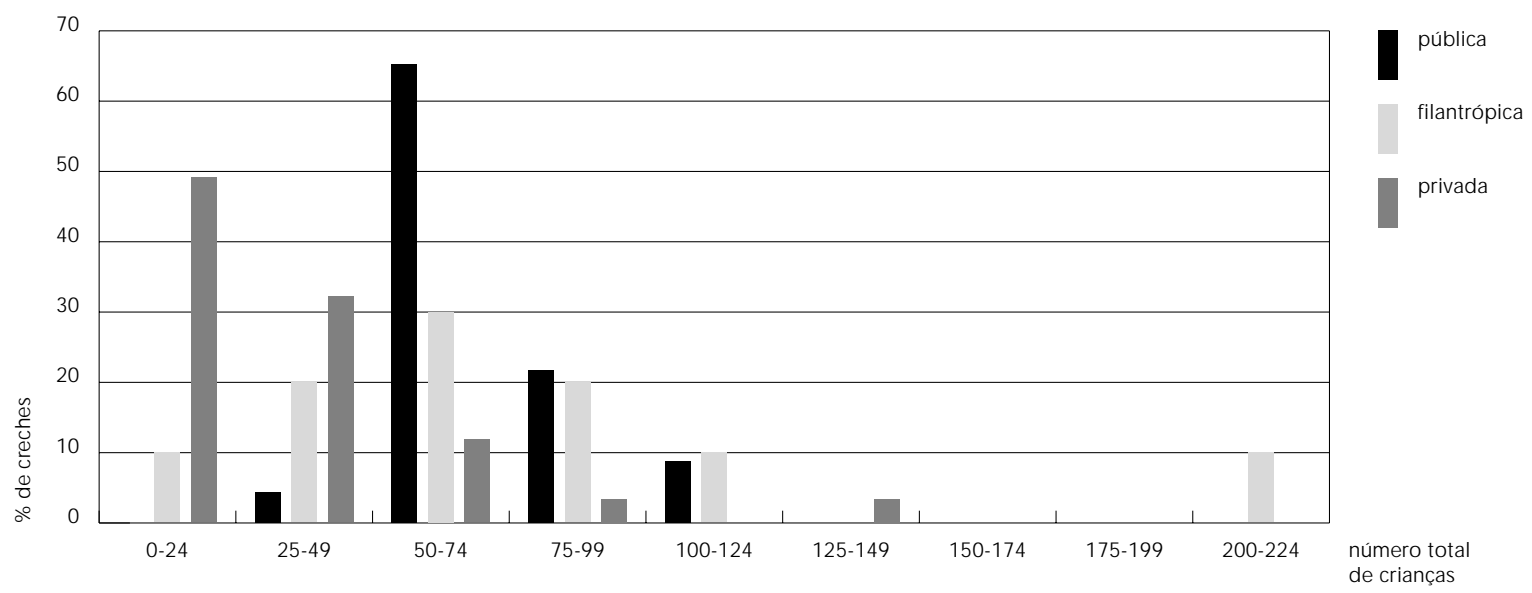


Tabela 1

Número total de grupos, número médio de crianças por grupo, número médio de crianças por monitora e respectivos números máximo e mínimo, classificados por nível dos grupos e tipo de financiamento das creches de Pelotas, Rio Grande do Sul.

\begin{tabular}{|c|c|c|c|}
\hline Característica & $\begin{array}{l}\text { Creche } \\
\text { Pública }\end{array}$ & $\begin{array}{l}\text { Creche } \\
\text { Filantrópica }\end{array}$ & $\begin{array}{l}\text { Creche } \\
\text { Privada }\end{array}$ \\
\hline \multicolumn{4}{|l|}{ Berçário } \\
\hline $\mathrm{N}$ o de grupos & 21 & 10 & 47 \\
\hline \multicolumn{4}{|c|}{$\mathrm{N}$ o de crianças por grupo } \\
\hline Média & 16,1 & 13,3 & 4,9 \\
\hline Mín-máx & $11-22$ & $6-24$ & $1-19$ \\
\hline \multicolumn{4}{|c|}{$\mathrm{N}$ o crianças por monitora } \\
\hline Média & 4,9 & 8,4 & 3,4 \\
\hline Mín-máx & $4-7$ & $5-15$ & $1-19$ \\
\hline \multicolumn{4}{|l|}{ Maternal } \\
\hline $\mathrm{N}$ o de grupos & 25 & 14 & 106 \\
\hline \multicolumn{4}{|c|}{$\mathrm{N}$ o de crianças por grupo } \\
\hline Média & 21,8 & 22,4 & 7,7 \\
\hline Mín-máx & $13-22$ & $8-45$ & $1-21$ \\
\hline \multicolumn{4}{|c|}{$\mathrm{N}$ o de crianças por monitora } \\
\hline Média & 7,9 & 14,5 & 6,6 \\
\hline Mín-máx & $5-13$ & $6-25$ & $1-20$ \\
\hline \multicolumn{4}{|l|}{$\mathrm{J}$ ardim } \\
\hline $\mathrm{N}$ o de grupos & 27 & 11 & 87 \\
\hline \multicolumn{4}{|c|}{$\mathrm{N}$ o de crianças por grupo } \\
\hline Média & 16,7 & 23,3 & 10,8 \\
\hline Mín-máx & $9-28$ & $11-35$ & $1-80$ \\
\hline \multicolumn{4}{|c|}{$\mathrm{N}$ o de crianças por monitora } \\
\hline Média & 10,2 & 20,8 & 9,6 \\
\hline Mín-máx & $5-20$ & $11-35$ & $1-28$ \\
\hline \multicolumn{4}{|l|}{ Pré } \\
\hline $\mathrm{N}$ o de grupos & 19 & 2 & 3 \\
\hline \multicolumn{4}{|c|}{ № de crianças por grupo } \\
\hline Média & 16,6 & 25,0 & 27,0 \\
\hline Mín-máx & $10-28$ & $15-35$ & $6-59$ \\
\hline \multicolumn{4}{|c|}{$\mathrm{N}$ o de crianças por monitora } \\
\hline Média & 11,4 & 25,0 & 27,0 \\
\hline Mín-máx & $5-20$ & $15-35$ & $6-59$ \\
\hline
\end{tabular}

maior para o jardim e pré. As creches privadas apresentaram grupos consistente e significantemente menores que os das creches públicas e filantrópicas, exceto o do pré, onde havia apenas três grupos. Para o berçário e maternal, o número médio de crianças por grupo foi cerca de três vezes maior nas creches públicas. Para o jardim, os grupos das creches públicas foram cerca de $50 \%$ maiores. As creches filantró- picas chamaram a atenção no tocante ao número máximo encontrado: 45 crianças por grupo para o maternal e 35 para o jardim.

As creches filantrópicas apresentaram relações de crianças por monitora significantemente maiores do que os outros dois grupos, com índices médios de 8,4 crianças por monitora no berçário, 14,5 no maternal, 20,8 no jardim e 25,0 no pré (este com apenas 2 grupos). E apesar de as creches públicas apresentarem, em média, grupos maiores do que as privadas, não houve diferença estatística entre elas em relação aos índices de crianças por monitora (Tabela 1).

A Tabela 2 mostra as proporções de grupos, para cada tipo de creche, que estavam acima do máximo recomendado para o índice de crianças por monitora, utilizando uma referência local (Rodrigues, 1992) e uma referência americana (CDC, 1996). Em relação ao projeto de lei municipal, muito menos exigente, praticamente todos os grupos em nível de maternal e jardim das creches públicas e privadas estavam dentro do recomendado. Cerca de $25 \%$ dos grupos de berçário das creches públicas e $15 \%$ dos grupos das creches privadas excederam o limite. As creches filantrópicas apresentaram uma situação pior, com $80 \%$ dos grupos de berçário e $36 \%$ dos grupos de maternal e jardim com valores acima do recomendado.

Tomando como referência as recomendações do CDC, praticamente todos os grupos das creches filantrópicas estavam acima do limite. Entre as creches públicas, todos os grupos de berçário e cerca de $66 \%$ dos grupos de maternal e jardim excediam o limite. Entre as privadas, estas proporções ficaram em 32\%, 47\% e 52\% para o berçário, maternal e jardim.

Especificamente para as creches privadas, realizou-se uma comparação das mensalidades cobradas para meio período e período integral. A maioria das creches (57\%) cobrava mensalidades entre 60 e 100 reais para freqüência em meio período, variando entre 25 e 133 reais. Entre as creches que oferecem período integral, a maioria (62\%) cobrava entre 100 e 160 reais de mensalidade, variando entre 60 e 240. Para meio período, o valor máximo foi 5,3 vezes maior do que o mínimo, e para período integral, o máximo foi quatro vezes o mínimo. Não se encontrou correlação significante entre o valor da mensalidade e a relação criança por monitora, para cada um dos níveis.

Encontrou-se uma maior especificidade de funções entre as creches públicas (Tabela 3). Em apenas 4\% delas as monitoras ajudavam a preparar refeições, e em nenhuma funcionários de cozinha auxiliavam no cuidado com as 
crianças. Estas proporções foram maiores para creches filantrópicas e privadas.

$O$ atendimento a crianças em caráter ocasional (modalidade localmente conhecida como estacionamento) foi relatado em $83 \%$ das creches públicas, $64 \%$ das privadas e $20 \%$ das filantrópicas (Tabela 3). Quando aceitas, estas crianças eram mantidas junto com as regulares.

\section{Segurança e estrutura física}

Extintores de incêndio estavam presentes em todas as creches públicas, $80 \%$ das filantrópicas e $81 \%$ das privadas. Havia, durante todo o período de funcionamento, ao menos um funcionário com treinamento sobre como agir em caso de incêndio em $22 \%$ das creches públicas, $40 \%$ das filantrópicas e $14 \%$ das privadas. Com relação a primeiros socorros, as proporções encontradas foram de $57 \%$, 70\% e $42 \%$, na mesma ordem (Tabela 3). Em ambos os casos, não houve diferença significante entre os tipos de creche. As entidades ou pessoas mais referidas como responsáveis pelo treinamento em primeiros socorros foram, em ordem decrescente de freqüência: enfermeiro, médico, SESI, Corpo de Bombeiros, profissional de ciências domésticas, auxiliar de enfermagem e SENAC.

A maioria das creches (82\%) aceitava crianças usando fral das, em proporções semelhantes entre os três grupos de financiamento. No entanto, fraldário (ambiente separado da sala de recreação, em que exista uma bancada específica para a troca de fraldas e uma pia com água corrente, podendo ser conjugado a um banheiro) estava presente em apenas 57\% e $60 \%$ das creches filantrópicas e privadas, respectivamente. Estas proporções foram significativamente inferiores à das creches públicas, entre as quais todas dispunham deste equipamento ( $p=0,002$; Tabela 3).

De forma semelhante, todas as creches públicas dispunham de banheiros de uso exclusivo das crianças (não compartilhado por funcionários), enquanto que em $30 \%$ das filantrópicas eem $38 \%$ das privadas os banheiros eram usados por crianças e funcionários ( $p=0,02$; Tabela 3).

Nenhuma das creches possuía um sistema de aquecimento central para ambiente. O uso de aquecedores elétricos no período de inverno foi relatado em $42 \%$ delas (Tabela 3 ). Aquecimento a gás era usado por 4 creches privadas (7\%).

Uma área de recreio coberta, de uso comum das crianças, estava presente em um número reduzido de creches públicas (13\%), em comparação com as filantrópicas (80\%) e privadas (69\%) ( $p<0,001$; Tabela 3$)$.
Tabela 2

Proporções (\%) de grupos com relação criança por monitora acima do recomendado por lei municipal de Pelotas, RS (Rodrigues, 1992), e por documento dos Centros para Prevenção e Controle das Doenças, Atlanta, EUA (CDC, 1996).

\begin{tabular}{lccc}
\hline $\begin{array}{l}\text { Nível do grupo } \\
\text { e referência }\end{array}$ & $\begin{array}{l}\text { Creche } \\
\text { Pública \% }\end{array}$ & $\begin{array}{l}\text { Creche } \\
\text { Filantrópica \% }\end{array}$ & $\begin{array}{l}\text { Creche } \\
\text { Privada \% }\end{array}$ \\
\hline $\begin{array}{l}\text { Berçário } \\
\text { Lei municipal* }\end{array}$ & 24 & 80 & 15 \\
$\quad$ Recomendação CDC** & 100 & 100 & 32 \\
Maternal & & & \\
Lei municipal & 0 & 36 & 1 \\
Recomendação CDC & 68 & 93 & 47 \\
J ardim & & & \\
Lei municipal & 0 & 36 & 1 \\
Recomendação CDC & 63 & 100 & 52 \\
\hline
\end{tabular}

* Relação máxima de 5:1, 15:1 e 25:1 crianças por monitora para o berçário, maternal e jardim, respectivamente.

** Relação máxima de 3:1, 7:1 e 8:1 crianças por monitora para o berçário, maternal e jardim, respectivamente.

Em todas as creches havia uma área externa para recreio. Houve grande variação, no entanto, nos equipamentos disponíveis nestas áreas. Brinquedos como balanço, gangorra e escorregador estavam presentes em 52 (88\%) das creches privadas, em 7 (70\%) das creches filantrópicas e em apenas 4 (17\%) das creches públicas ( $p<0,001$; Tabela 3 ). O equipamento presente com mais freqüência nas creches públicas (61\%) foi uma área ou caixa com areia. A quase totalidade das creches filantrópicas e privadas contavam com este equipamento $(90 \% \mathrm{e}$ $92 \%$ respectivamente).

\section{Qualificação do pessoal}

A Tabela 4 mostra diferenças marcantes encontradas entre os diferentes tipos de creches quanto ao grau de escolaridade das monitoras. Em $48 \%$ das creches públicas e $40 \%$ das filantrópicas havia monitoras sem o primeiro grau completo, contra apenas 3\% das privadas. Em 82\% destas creches, todas as monitoras tinham pelo menos iniciado o segundo grau. Em 39\% das creches públicas havia ao menos uma monitora com grau superior completo ou incompleto. Esta proporção foi de $60 \%$ para as creches filantrópicas e de $73 \%$ para as privadas. A associação entre tipo de creche e escolaridade das monitoras foi significante tanto para escolaridade mínima ( $p \varangle 0,001)$ como para máxima ( $p=0,004)$.

Todas as creches públicas, $97 \%$ das privadas e $80 \%$ das filantrópicas $(p=0,03$ ) referiram 
Tabela 3

Características das creches de Pelotas, Rio Grande do Sul, em relação à operação, segurança e estrutura física, por tipo de financiamento.

\begin{tabular}{|c|c|c|c|c|}
\hline Características & $\begin{array}{l}\text { Creche } \\
\text { Pública n (\%) }\end{array}$ & $\begin{array}{l}\text { Creche } \\
\text { Filantrópica n (\%) }\end{array}$ & $\begin{array}{l}\text { Creche } \\
\text { Privada n (\%) }\end{array}$ & Valor-p* \\
\hline Monitoras ajudam a preparar refeições & $1(4)$ & $2(20)$ & $10(17)$ & 0,3 \\
\hline Funcionários da cozinha ajudam a cuidar de crianças & 0 & $5(50)$ & $18(31)$ & 0,003 \\
\hline Aceita crianças em caráter ocasional & $19(83)$ & $2(20)$ & $38(64)$ & 0,003 \\
\hline Ao menos um funcionário com treinamento para incêndio & $5(22)$ & $4(40)$ & $8(14)$ & 0,1 \\
\hline Ao menos um funcionário com treinamento em primeiros socorros & $13(57)$ & $7(70)$ & $25(42)$ & 0,2 \\
\hline Aquecedores elétricos & $9(39)$ & $6(60)$ & $24(41)$ & 0,5 \\
\hline Fraldário com água corrente & $21(100)$ & $4(57)$ & $28(60)$ & 0,002 \\
\hline Banheiro exclusivo para crianças & $22(96)$ & $7(70)$ & $38(64)$ & 0,02 \\
\hline Recreio coberto & $3(13)$ & $8(80)$ & $41(69)$ & $<0,001$ \\
\hline $\begin{array}{l}\text { Brinquedos no recreio descoberto (balanço, gangorra, } \\
\text { escorregador, etc.) }\end{array}$ & $4(17)$ & $7(70)$ & $52(88)$ & $<0,001$ \\
\hline
\end{tabular}

* Valor-p para o teste do $\chi^{2}$.

Tabela 4

Escolaridade mínima e máxima das monitoras das creches de Pelotas, Rio Grande do Sul, por tipo de financiamento.

\begin{tabular}{|c|c|c|c|}
\hline $\begin{array}{l}\text { Escolaridade } \\
\text { das monitoras }\end{array}$ & $\begin{array}{l}\text { Creche } \\
\text { Pública n (\%) }\end{array}$ & $\begin{array}{l}\text { Creche } \\
\text { Filantrópica n (\%) }\end{array}$ & $\begin{array}{l}\text { Creche } \\
\text { Privada n (\%) }\end{array}$ \\
\hline Escolaridade mínima & & & $p<0,001^{*}$ \\
\hline 1o grau incompleto & $11(48)$ & $4(40)$ & $2(3)$ \\
\hline 1ㅇ grau completo & $12(52)$ & 0 & $3(5)$ \\
\hline $2 \underline{\text { og grau}} * *$ & 0 & $5(50)$ & $48(82)$ \\
\hline superior** & 0 & $1(10)$ & $6(10)$ \\
\hline Escolaridade máxima & & & $p=0,004^{*}$ \\
\hline 1o grau completo & 0 & $1(10)$ & 0 \\
\hline 2o grau** & $14(61)$ & $3(30)$ & $16(27)$ \\
\hline superior** & $9(39)$ & $6(60)$ & $43(73)$ \\
\hline
\end{tabular}

* Valor-p para teste do $\chi^{2}$.

** Grau completo ou incompleto. mento da fiscalização dos serviços e para a orientação de novos projetos de pesquisa na área. Muito provavelmente, estes resultados são válidos para municípios de médio porte com características semelhantes ao nosso, visto que fortes determinantes das características dos serviços oferecidos, como legislação, fiscalização e financiamento tendem a ser semeIhantes.

A tarefa de comentar os resultados encontrados é dificultada pela ausência de um parâmetro nacional, amplamente aceito, que determine os padrões mínimos para as diversas características dos serviços de cuidado infantil. Uma avaliação recente das legislações estaduais (Thiessen, 1997) mostrou que estes documentos abordam aspectos bastante diversos, preocupam-se prioritariamente em determinar normas para o funcionamento de estabelecimentos particulares (deixando de lado o sistema público) e apresentam exigências muito variadas em relação às características dos serviços. Apenas como ilustração, a relação máxima recomendada de crianças por monitora varia de 4:1 a 20:1 na faixa de 0 a 11 meses. Recomendações estrangeiras disponíveis, como a editada pelo CDC (1996), são mais completas, mas sua aplicação direta para nossa realidade é difícil e discutível.

Do ponto de vista operacional, este estudo evidenciou diferenças marcantes entre as creches públicas e privadas, do ponto de vista do número de crianças atendidas e do regime de freqüência. Estas diferenças são provavelmente causadas por especificidades da demanda e por questões de regulamentação, menos exi- 
gente para creches que funcionam em meio período.

Em relação ao número de crianças por monitora, um dos indicadores mais importantes de qualidade de cuidado na creche, não houve diferença entre creches públicas e privadas. Os resultados também sugerem que, nas creches públicas, há espaço para remanejamento de monitoras das classes de pré para classes de berçário, de forma a melhorar a relação criança por monitora neste último grupo, onde $24 \%$ das creches estiveram acima do limite proposto pela legislação municipal. As creches filantrópicas, por outro lado, necessitam de melhoria substancial neste item, pois uma proporção considerável delas apresentou números de crianças por monitora muito acima do recomendado, mesmo usando uma referência pouco exigente.

Entre as creches privadas, chamou a atenção a grande variabilidade do valor das mensalidades e a falta de associação deste com o número de crianças por monitora, que é um indicador de qualidade de cuidado e tem impacto direto no custo operacional da creche. Este achado sugere que talvez haja ainda muito espaço para a melhora da relação custo-benefício das creches privadas.

No tocante à escolaridade das monitoras, uma parcela grande das creches públicas contava com monitoras de baixa escolaridade, enquanto que as creches privadas apresentaram um quadro mais positivo. Não só a escolaridade, mas o treinamento das monitoras em educação infantil e sua orientação por pessoal especializado são aspectos de fundamental importância para que se ofereça às crianças um cuidado de qualidade e atividades que estimulem e propiciem o pleno desenvolvimento de suas potencialidades. Este cunho educacional é não só desejável, mas atribuído formalmente às creches na Lei de Diretrizes e Bases da Educação (Congresso Nacional, 1996). Desta forma, o treinamento e um melhor nível educacional das monitoras devem ser considerados como prioridade.
As creches privadas apresentaram características que indicam um nível de especificidade relativamente baixo, em termos de funcionários e infra-estrutura. Isto se evidenciou mediante uma proporção el evada de creches em que funcionários de cozinha auxiliam no cuidado das crianças e monitoras ajudam na preparação de refeições e lanches, bem como pela ausência de banheiros exclusivos para as crianças e de instalações adequadas para a troca de fraldas. Nestes aspectos, as creches públicas mostraram-se claramente superiores, com alta especialização de funções e prédios com instalações adequadas para o cuidado das crianças.

Também ficou evidente, em todas as creches, o baixo grau de preocupação com o conforto ambiental, uma vez que a maioria delas não faz uso de aquecedores de ambiente no inverno, rigoroso nesta região do país.

A preocupação com segurança também precisa aumentar. Apesar de a maioria das creches contar com extintores de incêndio, poucas dispõe de ao menos um funcionário treinado para situações de incêndio e uso dos extintores durante todo o período de funcionamento da unidade. Da mesma forma, boa parte das creches não conta com ao menos um funcionário treinado para prestar primeiros socorros às crianças. A segurança na creche, que envolve muito outros itens, deve ser tratada como prioridade na sua organização, regulamentação e fiscalização.

Concluindo, as creches oferecem um serviço de qualidade muito variável, e questões que vão da estrutura física às práticas de cuidado estão sendo negligenciadas, mesmo levandose em conta as limitações da legislação existente. É fundamental que esta seja aprimorada e que os serviços responsáveis pela orientação e fiscalização das creches exerçam de forma mais efetiva suas funções. Recomendamos também que sejam vistos como prioridades a melhor formação de monitoras, maiores investimentos na adequação das creches e no seu equipamento, e a conscientização dos seus gerentes e funcionários em relação a questões de segurança.

\section{Agradecimentos}

Este trabalho contou com o apoio do Consel ho Nacional de Desenvolvimento Científico e Tecnológico (CNPq) e do programa PIBIC/CNPq, através da concessão de bolsas de Iniciação Científica e Aperfeiçoamento. 
Referências

ALEXANDER, C. S.; ZINZELETA, E. M.; MacKENZIE, E. J.; VERNON, A. \& MARKOWITZ, R. K., 1990. Acute gastrointestinal illness and child care arrangements. American Journal of Epidemiology, 131: 124-131.

BARROS, A. J. D., 1996. Health Risks Among Child Day Care Centre Attenders: The Role of Day Care Centre Characteristics in Common Childhood IIInesses. Ph.D. Thesis, London: Department of Epidemiology and Population Sciences, University of London (London School of Hygiene and Tropical Medicine).

BARROS, A. J. D.; HALPERN, R. \& MENEGON, O. E., 1998. Creches públicas e privadas de Pelotas, RS: Aderência à norma técnica. Jornal de Pediatria, 74:397-403.

BARROS, A. J. D., 1999. Child care attendance and common morbidity: Evidence of association in the literature and design issues. Revista de Saúde Pública, 33:98-106.

CDC (Centers for Disease Control and Prevention), 1996. The ABC's of Safe and Healthy Child Care. A Handbook for Child Care Providers. Atlanta: CDC.

BRASIL, 1996. Lei de Diretrizes e Bases da Educação (LDB). Lei Federal 9394, de 20 de dezembro de 1996. Porto Alegre: Secretaria Estadual da Educação.

FONSECA, W.; KIRKWOOD, B. R.; BARROS, A. J. D.; MISAGO, C.; CORREIA, L. L.; FLORES, J. A. M.; FUCHS, S. \& VICTORA, C. G., 1996. Attendance at day care centers increases the risk of childhood pneumonia among the urban poor in Fortaleza, Brazil. Cadernos de Saúde Pública, 12:133-140.

GOVERNO DO ESTADO DO RIO GRANDE DO SUL, 1990. Secretaria Estadual da Saúde e do Meio Ambiente. Portaria no 01/90; Norma Técnica no 26. Exigências Mínimas para Funcionamento de Cre ches, Maternais e Jardins de Infância. Porto Alegre: Governo do Estado do Rio Grande do Sul.
HASKINS, R. \& KOTCH, J., 1986. Day care and illness: Evidence, cost, and public policy. Pediatrics, 77: 951-982.

HILLIS, S. D.; MIRANDA, C. M.; MCCANN, M.; BENDER, D. \& WEIGLE, K., 1992. Day care center attendance and diarrheal morbidity in Colombia. Pediatrics, 90:582-588.

HOLADAY, B.; WAUGH, G.; MOUKADDEM, V. E.; WEST, J. \& HARSHMAN, S., 1995. Fecal contamination in child day care centers: Cloth vs paper diapers. American Journal of Public Health, 85:3033.

IBGE (Fundação Instituto Brasileiro de Geografia e Estatística), 1996. Contagem Nacional da População - 1996. SIDRA - Sistema IBGE de Recuperação Automática. 23 de fevereiro de 1998 «ttp:// www.sidra.ibge.gov.br/ >.

MARBURY, M. C.; MALDONADO, G. \& WALLER, L., 1997. Lower respiratory illness, recurrent wheezing, and day care attendance. American Journal of Respiratory and Critical Care Medicine, 155: 156-161.

MINISTÉRIO DA SAÚDE, 1989. Normas para Construção e Instalação de Creches. Portaria Ministerial 321, de26 demaio de 1988. Brasília: Centro de Documentação do Ministério da Saúde.

OSTERHOLM, M. T.; REVES, R. R.; MURPH, J. R. \& PICKERING, L. K., 1992. Infectious diseases and child day care. Pediatric Infectious Disease Journal, 11:S31-S41.

RODRIGUES, R. A., 1992. Projeto de lei no 141/92. Pelotas: Câmara Municipal.

THIESSEN, M. L., 1997. A Educação Infantil nas LegisIações Estaduais. Brasília: Ministério da Educação e do Desporto.

VICTORA, C. G.; FLORES, J. A.; FONSECA, W. \& KIRKWOOD, B. R., 1994. Risk factors for pneumonia among children in a Brazilian metropolitan area. Pediatrics, 93:977-985. 